\title{
Stem Cell from Human Exfoliated Deciduous Teeth (SHED) versus Human Umbilical Cord Blood Mononuclear Cells (cbMNC) Transplantation in Neural Damage Reduction in Rat Model of Cerebral Ischemia
}

\author{
Yetty Ramli ${ }^{1 *}$, Salim Harris ${ }^{1}$, Ahmad Sulaiman Al Wahdy ${ }^{1}$, Nandini Phalita Laksmi*1, \\ Mohammad Kurniawan', Masagus Zainuri², Ratih Rinendyaputri², Puspita Eka Wuyung ${ }^{3}$ \\ ${ }^{1}$ Department of Neurology, Faculty of Medicine, Universitas Indonesia, Jakarta, Indonesia \\ ${ }^{2}$ Center for Research and Development of Biomedical and Basic Health Technology, National Institute \\ Health Research and Development, Ministry of Health Republic of Indonesia, Jakarta, Indonesia \\ ${ }^{3}$ Department of Anatomic Pathology, Faculty of Medicine, Universitas Indonesia, Jakarta, Indonesia \\ *Corresponding author: n.phalita@gmail.com
}

\begin{abstract}
Ischemic stroke is one of major cause of mortality and disability in Indonesia. Stem Cells are considered as a promising therapy for ischemic stroke. In this study, we compared therapeutic potency of Stem cell from human exfoliated deciduous teeth (SHED) and Human umbilical cord blood mononuclear cell (cbMNC) using rat models of ischemic stroke. Following middle cerebral artery occlusion (MCAO), twenty male wistar rats were divided into four groups : normal rats $(n=5)$, rats undergone permanent MCAO $(n=5)$ as the control (stroke) group, rats undergone permanent MCAO and SHED transplantation $(n=5)$ and rats undergone permanent MCAO and cbMNC transplantation $(n=5)$ as the treatment group. SHED transplantation was performed at the acute phase after MCAO by intravenous injection. Histopathological evaluation of the neuron death ratio with hematoxylin and eosin staining confirmed that there was no significant differences at comparative study of neuron death ratio in rats transplanted with SHED and rats transplanted with $\operatorname{cbMNC}(\mathrm{p}=0,81)$. SHED and cbMNC transplantation at acute stroke showed reduction in the neuron death ratio in the brain of rat models with ischemic stroke, and may provide an opportunity for neuroprotection and neural regeneration after ischemic stroke.
\end{abstract}

\section{Keywords : cbMNC, Cell transplantation, Ischemic stroke, MCAO, SHED}

\section{INTRODUCTION}

Ischemic stroke is one of major cause of mortality and disability worldwide, particularly in Indonesia (Johnson, 2016; RISKESDAS, 2013). The incidence of stroke is increasing, and over the last four decades, the incidence was doubled in low- and middle-income countries, and mainly affect individuals at their productive age (Johnson, 2016). The prevalence of stroke in Indonesia in 2013 is 12,1 per 1000 population according to basic medical Research (RISKESDAS) (RISKESDAS, 2013).

The increasing number and the burden caused by stroke makes the need for effective therapy for neurorestoration and neural regeneration after 
ischemic stroke. Stem cell transplantation may provide a promising opportunity for its neuroprotective effects and its potential for replacing the damaged neurons after ischemic stroke, thus enhancing neurological outcomes (Wei et al., 2013). Stem cell from human deciduous teeth (SHED) are mesenchimal stem cells, which extracted from the pulp of exfoliated deciduous teeth (Rossa et al., 2016). Previous studies suggested that SHED has potential to differentiate into neurons in vitro, and has a high proliferation capability.

SHED also suggested have paracrine effects such as facilitated the differentiation of endogen stem cells. SHED can secrete neurotrophic factors that enhance neurogenesis and angiogenesis after ischemic stroke. SHED also applicable for autologous tissue regeneration without the risk of immune reactions. SHED extraction is less invasive, and it is superior for their easy isolation, expansion, storage, and raise less ethical issues than other stem cell sources (Mita et al., 2015; Wei et al., 2013).

While Human umbilical cord blood mononuclear cell (cbMNC) is also a potential source for cell-based therapy for ischemic stroke. cbMNC proved to have contribution to neurogenesis and angiogenesis after ischemic stroke (Fruchtman et al., 2004). From previous studies, cbMNC proved can decrease apoptosis, reduce inflammation in periinfarct area, and stimulate angiogenesis, so that it can improve functional recovery when transplanted to rat models of ischemic stroke (Fruchtman et al., 2004; Ringden et al., 2008).

This research was conducted to compare therapeutic potency of Stem cell from human exfoliated deciduous teeth (SHED) and Human umbilical cord blood mononuclear cell (cbMNC) using rat models of ischemic stroke. In this study, we investigate whether intravenous administration of SHED and cbMNC can reduce neuronal death in the infarcted area of brain after ischemic stroke. The aim of this study is to provide optimal therapy for ischemic stroke.

\section{METHODS}

This is a clinical trial using a prospective interventional approach on SHED and cbMNC transplantation in animal models (Wistar rats) with ischemic stroke. Twenty male wistar rats were divided into four groups : normal rats $(\mathrm{n}=5)$, rats undergone permanent MCAO $(n=5)$ as the control (stroke) group, rats undergone permanent MCAO and SHED transplantation $(\mathrm{n}=5)$ and rats undergone permanent MCAO and cbMNC transplantation $(n=5)$ as the treatment group. SHED transplantation was performed at the acute phase after MCAO by intravenous injection. Evaluation of the death neurons ratio in brain cortex area was done using Hematoxylin and Eosin (HE) staining.

\section{Permanent Middle Cerebral Artery Occlusion Procedure}

For ischemic stroke induction, rats underwent a permanent Middle Cerebral Artery Occlusion (MCAO). Before MCAO procedure conducted, rats were anesthetized with ketamine (80 $\mathrm{mg} / \mathrm{kg})$ and xylazine $(10 \mathrm{mg} / \mathrm{kg})$ by intramuscular injection. The rats were positioned in supine position. Midline insicion was performed, common carotid artery (CCA) was isolated from the vagus nerve, then 
permanent knots were placed. After the bifurcation of CCA, external carotid artery, and internal carotid artery were identified, permanent knots were placed on the CCA, and the external carotid artery was ligated permanently. After that, we performed an incision at the bifurcation to insert the monofilament 4.0 , then a permanent knot was placed to avoid the monofilament out of its track (Fruchtman et al., 2004).

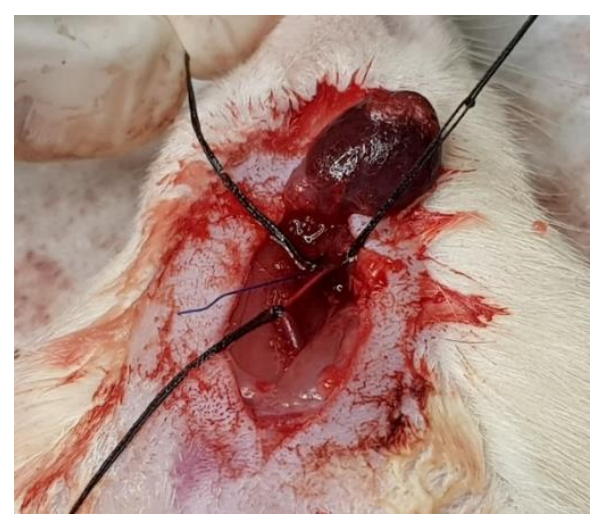

Figure 2.1 Permanent Middle Cerebral Artery Occlusion (MCAO) procedure

\section{Histopathological Asessment of Dead Neuron Ratio at The Brain Cortex}

Histopathological assessment of dead neuron ratio at the brain cortex of rats model of ischemic stroke conducted by hematoxyline \& Eosin staining, at 21 days after stem cell transplantation. The experimental animals were euthanized at day 21 after transplantation, the animal's brain were isolated and cut coronally. The coronal sections were stained with hematoxylin \& eosin. Image $\mathbf{J}$ software by the National Institute of Health (NIH) was used to calculate dead neurons and intact neuron in the brain cortex area. The neuron death ratio was calculated by using the formula : Neuron death ratio $=($ The number of death neurons/death neurons + normal neurons). The calculation conducted at the brain cortex area, in five visual areas, with a consisten location.

\section{RESULTS}

Histopathological evaluation of the neuron death ratio with hematoxylin and eosin staining confirmed that there were significant differences of neuron death ratio in Stroke+SHED group compared to stroke group $(\mathrm{p}<0,001)$ at 21 days after MCAO.

Table 1. The Neuron Death Ratio in the Cortex Area after SHED Transplantation

\begin{tabular}{cccc}
\hline & \multicolumn{2}{c}{ Mean \pm SD } & p-Value \\
\cline { 2 - 3 } & $\begin{array}{c}\text { Stroke } \\
\text { Group }\end{array}$ & $\begin{array}{c}\text { Stroke+SHED } \\
\text { Group }\end{array}$ & \\
\hline Neuron & 0.74 & $0.40(0.08)$ & $<0.001$ \\
$\begin{array}{l}\text { Death } \\
\text { Ratio }\end{array}$ & $(0.01)$ & & \\
\hline **Normal distribution of all groups & \\
*Using T Test Analysis & &
\end{tabular}

There was also significant differences of neuron death ratio in Stroke+cbMNC group compared to Stroke group $(\mathrm{p}<0,05)$ at 21 days after MCAO.

Table 2. The Neuron Death Ratio in the Cortex Area After cbMNC Transplantation

\begin{tabular}{|c|c|c|c|}
\hline & \multicolumn{2}{|c|}{ Mean \pm SD } & \multirow{2}{*}{$\begin{array}{c}\mathrm{p}- \\
\text { Value }\end{array}$} \\
\hline & $\begin{array}{l}\text { Stroke } \\
\text { Group }\end{array}$ & $\begin{array}{c}\text { Stroke+cbMNC } \\
\text { Group }\end{array}$ & \\
\hline $\begin{array}{l}\text { Neuron } \\
\text { Death } \\
\text { Ratio }\end{array}$ & $\begin{array}{l}0.74 \\
(0.01)\end{array}$ & $0.43(0.29)$ & $<0.05$ \\
\hline
\end{tabular}

**Normal distribution of all groups

*Using T Test Analysis

Histopatological evaluation confirmed there was no significant differences at comparative study of neuron death ratio in rats transplanted with SHED and rats 
transplanted with cbMNC $(\mathrm{p}=0,81)$, indicated that SHEd and cbMNC transplantation effect were similar for neuronal death reduction after ischemic stroke.

Table 3. Comparative Study of Neuron Death Ratio After SHED Transplantation and cbMNC Transplantation

\begin{tabular}{llcc}
\hline & \multicolumn{2}{c}{ Mean \pm SD } & p- \\
\cline { 2 - 3 } & $\begin{array}{c}\text { Stroke+SH } \\
\text { ED Group }\end{array}$ & $\begin{array}{c}\text { Stroke+cbM } \\
\text { NC Group }\end{array}$ & \\
\hline $\begin{array}{l}\text { Neuron } \\
\text { Death } \\
\text { Ratio }\end{array}$ & $0.40(0.08)$ & $0.43(0.29)$ & 0.81 \\
**Normal distribution of all groups & \\
*Using T Test Analysis & &
\end{tabular}

\section{DISCUSSION}

Our study demonstrated that both SHED and cbMNC transplantation reduced neuron death ratio in the acute phase in animal model of ischemic stroke. The comparative study of neuron death ratio in rats transplanted with SHED and cbMNC confirmed no significant differences, indicated that SHED and cbMNC transplantation effect were similar for neuronal death reduction after ischemic stroke.

This beneficial effects of SHED and cbMNC on the acute phase of ischemic stroke might be explained by neuroprotective and neurogenesis induction capacity of stem cells (Chen et al., 200). In experimental models of stroke, there were a number of studies demonstrated mesenchymal and mononuclear stem cells capacity to secrete various trophic factors, to induce neurogenesis, neuroprotection, and angiogenesis (Ikegame et al., 2011). Thus, SHED and cbMNC can be a good cell source for ishemic stroke therapy. As adult stem cells, among the variety of stem cells sources, SHED and cbMNC could avoid several ethical issues, immune rejection, and tumor formation (Ikegame et al., 2011; Pittenger et al., 1999).

Based on the study conducted by Lei et al, cbMNC transplantation in the hyperacute phase of ischemic stroke improved behavioural assessment and infarct volume. The study also obtained evidence that cbMNC transplantation improves regional $\mathrm{CBF}$, cerebrovascular reactivity, and vascular remodeling, thus can induced vasculogenesis (Lei et al., 2017). There was similar result on the study conducted by Ramli et al (2017), cbMNC transplantation intraarterially and intravenously on the rat with ischemic stroke obtained improvement on neuron death ratio on both groups, but there was a significant difference in the neuron death ratio at the group transplanted cbMNC intraarterially (Ramli et al., 2017).

The result of this study similar with the study conducted by Zhang et al, SHED transplantation can reduce neuronal death, reduce apoptosis, and improve neuropathologic score (Zhang et al., 2018). Inoue et al also reported that SHED can migrate and differentiate into endogen neuronal progenitor cells, that can repair neural damage caused by ischemic process (Inove et al., 2013).

From this study and previous studies, neuronal death reduction after stem cell transplantation prove the paracrine effects of transplanted stem cells. The paracrine effects thought can modulate neurogenesis, angiogenesis, and neuroplasticity at the brain after ischemic stroke (Zhang et al., 2018; Mita et al., 2015). The transplanted stem cells proved can causes secretion of some factors. The factors secreted after stem cell 
transplantation that facilitate paracrine effects were chemokine stromal cell-derived factor-1 (SDF-1) that induce stem cell migration to the infarcted area, Neuron Growth Factor (NGF) and Brain-derived Neurotrophic factor (BDNF) that induce neurogenesis, and Vascular Endothelial Growth Factor (VEGF) that induce agiogenesis. The factors secreted by stem cells thought to have function in inducing endogenous stem cells in neurogenesis dan angiogenesis after cerebral ischemia (Zhang et al., 2018; Mita et al., 2015).

SHED and cbMNC both have shown efficacy on many preclinical study for treating stroke. From the study conducted by Boltze et al, cbMNC transplantation intravenously at the acute phase of stroke can improved behavioural function (Lei et al., 2017; Iskander et al., 2013). From the study by Iskander et al, intravenous injection of cbMNC can reduced infarct volume of rats model of ischemic stroke (Iskander et al., 2013). Yamagata et al reported that SHED transplantation can reduce apoptotosis, so that reducing brain damage and improve functional outcome on ischemic rats brain (Yamagata et al., 2013).

This study have some limitation. We can't be sure wheter the beneficial effects of SHED and cbMNC transplantation explained by stem cells differentiation into new neural/vascular lineage cells, or it obtained by paracrine effects of humoral factors secreted by the stem cells. Future studies also needed to evaluate neurogenesis, angiogenesis, and apoptosis marker by immunohistochemistry evaluation.

\section{CONCLUSION}

SHED and cbMNC transplantation intravenously at the acute phase of stroke showed similar effects on neural damage reduction in the brain of rat models with ischemic stroke. SHED and cbMNC may provide an opportunity for neuroprotection and neural regeneration after ischemic stroke. Future studies is needed to evaluated SHED cbMNC transplantation effects immunohistochemistrically.

\section{REFERENCES}

Badan Penelitian dan Pengembangan Kesehatan. Riset Kesehatan Dasar (RISKESDAS) 2013 Lap Nas 2013. 1-384.

Boltze J, Schmidt UR, Reich DM, Kranz A, Reymann KG, Strassburger M, et al 2012 Determination of the therapeutic time window for human umbilical cord blood mononuclear cell transplantation following experimental stroke in rats. Cell Transplant 21 1199-211

Chen J, Li Y, Katakowski M, Chen X, Wang L, Lu D, et al 2003 Intravenous bone marrow stromal cell therapy reduces apoptosis and promotes endogenous cell proliferation after stroke in female rat. J Neurosci Res 73778 86.

Chen J, Zhang ZG, Li Y, Wang L, Xu YX, Gautam SC, et al 2003 Intravenous administration of human bone marrow stromal cells induces angiogenesis in the 
ischemic boundary zone after stroke in rats

Circ Res 92 : 692 - 9.

Fruchtman SM, Hurlet A, Dracker R, Isola L, Goldman B, Schneider BL, Emre S 2004 The successful treatment of severe aplastic anemia with autologous cord blood transplantation. Biol Blood Marrow Transplant 10 741-2

Ikegame Y,et al 2011 Comparison of mesenchymal stem cells from adipose tissue and bone marrow for ischemic stroke therapy Cytotherapy 13 675-85.

Inoue $\mathrm{T}$, Sugiyama $\mathrm{M}$, Hattori $\mathrm{H}$, Wakita $\mathrm{H}$, Wakabayashi T, Ueda M 2013 Stem Cells from Human Exfoliated Deciduous Tooth-Derived Conditioned Medium Enhance Recovery of Focal Cerebral Ischemia in Rats Tissue Eng Part A 19 1-2.

Iskander A, Knight RA, Zhang ZG, Ewing JR, Shankar A, Varma NR, et al 2013 Intravenous administration of human umbilical cord blood-derived AC133+ endothelial progenitor cells in rat stroke model reduces infarct volume:magnetic resonance imaging and histological findings. Stem Cells Transl Med 2 703-14.

Johnson W, Onuma O, Owolabi M, Sachdev S 2016 Stroke: A global response is needed. Bulletin of the World Health Organization.
Mita T, Furukawa-Hibi Y, Takeuchi H, Hattori H, Yamada K, Hibi H, et al 2015 Conditioned medium from the stem cells of human dental pulp improves cognitive function in a mouse model of Alzheimer's disease. Behav Brain Res.

Lei, et al 2017 Intraarterial transplantation of human umbilical cord blood mononuclear cells in hyperacute stroke improves vascular function. Stem Cell Research \& Therapy 8:74

Pittenger MF, Mackay AM, Beck SC, Jaiswal RK, Douglas R, Mosca JD, et al 1999 Multilineage potential of adult human mesenchymal stem cells Science 284143 - 7

Ramli Y, Alwahdy AS, Kurniawan M, Juliandi B, Wuyung PE, Bilianti Susanto YD 2017 Intravenous Versus Intraarterial Transplantation of Human Umbilical Cord Blood Mononuclear Cells for Brain Ischemia in Rats HAYATI J Biosci 24 187-94

Ringden O, Okas M, Uhlin M, Uzunel M, Remberger M, Mattsson J 2008 Unrelated cord blood and mismatched unrelated volunteer donor transplants, two alternatives in patients who lack an HLA-identical donor. Bone Marrow Transplant $\mathbf{4 2}$ 643-8

Rosa V, Dubey N, Islam I, Min KS, Nor JE 2016 Pluripotency of Stem Cells from Human Exfoliated Deciduous Teeth for Tissue Engineering. Stem Cells International 1-6. 
Wei X, Xue Y, Zhi-peng H, Fan-fang Q, Li S, Yufang S 2013 Mesenchymal stem cells: a new trend for cell therapy. Acta Phamacol Sin 34 747-54.

Yamagata M, Yamamoto A, Kako E, Kaneko N, Matsubara K, Sakai K, et al 2013 Human dental pulp-derived stem cells protect against hypoxic-ischemic brain injury in neonatal mice Stroke 44 551-4.

Zhang X, Zhou Y, Li H, Wang R, Yang D, Li B, et al 2018 Transplanted Dental Pulp Stem Cells Migrate to Injured Area and Express Neural Markers in a Rat Model of Cerebral Ischemia. Cell Physiol Biochem 